\title{
Changing landscapes: Responding to domestic violence in New Zealand
}

\author{
Yoonne Crichton-Hill
}

Yoonne Crichton-Hill is a Senior Lecturer with the Social Work programme, School of Social and Political Sciences at the University of Canterbury. Her work experience is in child protection and domestic violence, and her teaching and research are in the areas of violence and culturally responsive social work.

\section{Abstract}

Domestic violence is not a recent phenomenon; rather it is one which has endured. To understand professional social work responses to domestic violence it is necessary to examine theories of causation since these inform ideas about intervention. How social work responds to domestic violence is context dependent. This article examines the causal explanations and contextual factors that have shaped New Zealand's social work response to domestic violence. Suggestions are made for maximising a multifaceted, anti-discriminatory approach to practice.

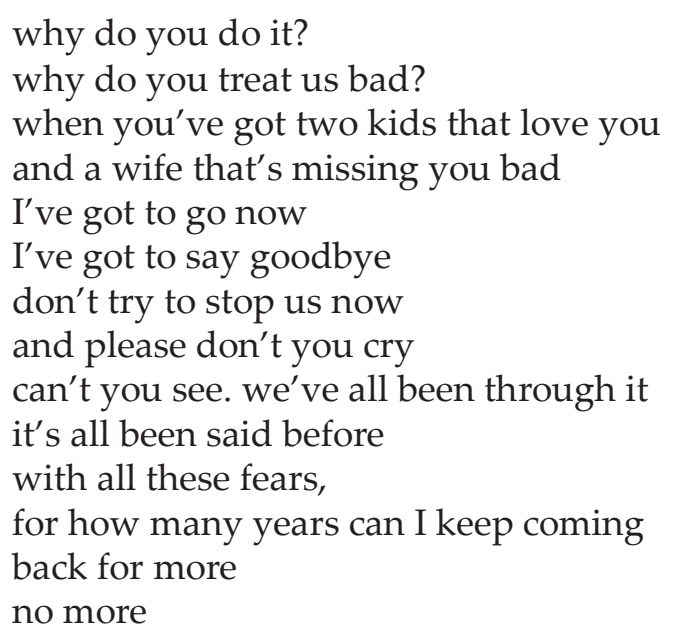

must be addicted to all this pain cause I keep coming back for the shame dear god give me the strength to leave I've got to keep going, keep going this time (Ricketts \& Childs, 1991).

This song expresses the confusion, pain and shame a woman feels as the result of domestic violence at the hands of her husband; it communicates her prayers that she might be strong enough to leave ... this time.

Domestic violence in Aotearoa New Zealand has, for some time, been recognised as a significant social problem. Our responses to domestic violence have been varied and reflective of our changing demographics and context. One way of understanding our current social 
work approaches to the problem of domestic violence is to reflect on the journey we have taken to get here; that is, to trace how we have explained domestic violence (the theory) over time and the responses arising out of these explanations.

So what is theory? Generally theory is described as a way of explaining a phenomenon (Sheldon \& Macdonald, 2009; Walsh, 2006). Theories are abstract ideas that include notions about what social work intervention strategies may be effective with clients (Walsh, 2006 p.4). These abstract ideas can be divided into higher and lower levels:

Theories at higher levels of abstraction provide general ideas for understanding and/or intervening with a wide range of human behavior ... Theories at lower levels of abstraction provide more specific ideas for understanding and/or intervening with a more circumscribed range of human behavior (e.g., the theory of interactive trauma/grief-focused therapy ... (Coady \& Lehmann, 2008, p. 42).

Social workers recognise that there is a strong link between theory and practice. As Shardlow (2007) suggests 'Social workers are expected to have a broadly-based professional understanding that integrates knowledge derived from a range of academic and professional disciplines into a coherent and usable form, which can be directly applied in practice' ( $p$. 13). One framework for thinking about the link between theory and practice moving from high level abstractions (practice theory), to day-to-day practice activities (intervention) is provided by Walsh (2006). Thus applied to domestic violence:

- Practice Theory (general ideas about domestic violence).

- Practice Model (strategies for working with types of clients - for example, with women who have experienced domestic violence).

- Practice Strategy (strategies for working with an individual client).

- Intervention (activities undertaken with the individual client).

For the purposes of this article the focus will be on the first two aspects of the framework - practice theory and practice model.

\section{Practice theories of domestic violence}

There are a number of theories about domestic violence, all of which are reflective of the cultural context in which they were developed. Practice theories can be divided into microoriented and macro-oriented theories.

\section{Micro-oriented: Social learning}

Micro-oriented explanations attempt to explain domestic violence as the result of individual characteristics and therefore draw on developmental and personality theories. Micro-oriented explanations propose that a number of interrelated individual factors explain why domestic violence occurs. These factors may include personal abuse history, personality disorders, low self esteem and substance misuse. An example is social learning theory.

Social learning theory suggests that behaviour is learned through modelling. Therefore, men's violence against women is the result of lessons learned in childhood. The learning (that violence is acceptable) is reinforced through reward, repetition and the avoidance of punishment (Verrill, 2008; Fisher \& Lab, 2010). Bandura (1973, 1977, 1979) maintains that 
the key three influences on aggression are origins, instigators and maintainers. The influence of origins refers to the way in which individuals attain aggressive behaviour through observational learning (modelling), particularly in childhood, and transmit this knowledge to apply in a range of situations. Furthermore, for aggression to occur there must be an instigator. Instigators may be emotional threat or insult, physical attack, or economic deprivation, enforced obedience or mental illness (Renfrew, 1997). Finally, once aggressive behaviours are attained they are maintained by a range of factors including positive reward, such as improved social status, and through negative reinforcement, such as escape from harm. Aggressive behaviour may also be maintained when an individual experiences others being rewarded for aggression, thereby raising expectations that they will be equally rewarded, or when an individual feels satisfaction as a result of aggressive behaviour.

Social learning theory offers an explanation for the intergenerational transmission of violence. It has been suggested that social learning theory and its contribution to understanding intergenerational transmission of abuse has been largely accepted without question (Stith Rosen, Middleton, Busch, Lundeberg, \& Carlton, 2000). The exact way in which patterns are transmitted from generation to generation is unclear in that there is little evidence of what specific cognitive, psychological, social and biological processes are involved (Hearn, 1998). Overall, little attention has been paid to critically examining the rigor of empirical research in support of social learning theories and intergenerational transmission of violence.

\section{Macro-oriented explanations: Feminism}

Macro-oriented explanations, on the other hand, examine the social and cultural conditions in society that create and maintain domestic violence. The most prominent (in the domestic violence field) of the theories in this grouping are feminist explanations.

From the 1960s the women's movement highlighted a number of challenges facing women in New Zealand. The early 1970s has been described as a time of 'radicalism and militancy in the cause of women' (Dann 1985, p.24). During this time the Women's Liberation Conference was held; the second women's liberation magazine (Broadsheet) began publication; women protested about a number of issues - including domestic violence. The first New Zealand women's refuge was established in 1974 (Dann 1985).

Until 1970 the police did not intervene in domestic violence unless there was a serious injury or death (Ford, 1993). In the 1970s police became more involved in domestic disputes, however, the involvement was negligible and police generally held a mediating role between the two parties in order to pacify the situation and stop the violence. Generally, charges were not laid (Cross \& Newbold, 2010). Furthermore, it was only in 1985 that rape within marriage became a criminal offence (New Zealand Committee of Inquiry into Violence, 1987).

Feminist explanations of domestic violence situate violence in a gender defined context within which power is a key aspect. It signifies a rejection of individual pathological explanations of domestic violence. Bograd (1988) suggests there are three ideas that are common to all feminist perspectives of domestic violence. Firstly, that the family is an institution which may promote and maintain domestic violence. Secondly, in order to comprehend domestic violence it must be conceptualised in ways that reflect women's experience. Finally, feminist perspectives of domestic violence are dedicated to advocating for women and developing theories which accurately reflect women's experiences. 
Feminist analysis develops from an understanding that overwhelmingly domestic violence is carried out by men towards women. This, feminists suggest, reflects a patriarchal societal structure aimed at subordinating women (McPhail, Busch, Kulkarni \& Rice, 2007). This patriarchal structure is maintained through the process of socialisation which advocates for traditional male and female roles where 'femininity is strongly associated with conquest and masculinity with domination' (Cribb, \& Barnett, 1999, p 51).

Methods of control are not confined to physical violence. According to Schecter (1982) other strategies, including verbal abuse, withdrawing of affection and economic control, are used when men believe it is unacceptable to physically abuse women. The Duluth power and control wheel has developed this idea further and seeks to explain how a range of tactics are purposefully employed by men to reinforce control (Crichton-Hill, 2001). These tactics include intimidation, verbal abuse, threatening, economic abuse and using children. In this sense violence is seen to be part of a continuum of methods used to oppress women.

\section{Multifaceted explanations}

It is now recognised that no theoretical explanation on its own can sufficiently supply us with the answers to the question 'What causes domestic violence?' To help shape our social work responses to both women victims and male perpetrators of domestic violence we must also consider the cultural context within which the violence is taking place. Therefore we must consider New Zealand context and culture.

Since colonisation, decisions have tended to be made for Maori, not by Maori (New Zealand Ministerial Advisory Committee, 1986). The result, stated the New Zealand Ministerial Advisory Committee, is the collapse of traditional Maori society. In relation to the role of women, Balzer, Haimona, Henare, \& Matchitt (1997) state:

Colonialism attempted to destroy kinship patterns that were not modelled on nuclear family structures, disrupting, in the process, female organisations that were based on kinship systems which allowed more power and autonomy to women than those of the colonising nation. ( $p$ $51)$.

During the 1980s, New Zealand underwent a number of economic and social changes. One outcome of this was an increase in Maori rates of unemployment and a drop in Maori household income. As Blakely, Ajwani, Robson, Tobias, \& Bonne, (2004) suggest:

These social and macroeconomic changes did not impact equally on Maori and non-Maori. Indeed, inequalities between Maori and non-Maori widened in employment status, education, income, and housing - key social determinants of health (https://www.nzma.org.nz/journal/117-1199/995/).

Internationally state departments were becoming corporatised, reasonably autonomous entities contracting for services (devolution and privatisation); and New Zealand followed this trend.

The New Zealand Ministerial Advisory Committee report, Puao-te-Ata-tu (1986) was one of a number of actions that promoted change in the way social services responded to Maori. Indigenous ideas grew in strength as Maori development was viewed as a way of being liberated from colonisation. At the first Hui Taumata (Maori Economic Summit) in 
1984 a number of social and economic issues were discussed including welfare dependency and tino rangatiratanga. This Hui led to what has been termed a 'cultural and economic renaissance for Maori' (Hudson, cited in Durie, 2005, p. ii). So while the social and economic changes impacted negatively on Maori, at the same time devolution of services created the opportunity for the development of Maori solutions to Maori problems. Prior to the 1980s there were very few Maori providers of social services; 30 years later there are many. Durie (2005) identifies this as a 'transformation'. In the domestic violence arena we see as part of this movement a separation of intervention approaches in Women's Refuge with the development of tau iwi and Maori parallel service.

Alongside the developments in Maori services has been the creation of a national family violence prevention strategy. A number of areas of action to eliminate violence and improve service delivery were established under Te Rito: The New Zealand Family Violence Prevention Strategy (2002), developed by the Ministry of Social Development (MSD). The New Zealand Family Violence Clearinghouse, also an outcome of Te Rito, has an up-to-date database of family violence information and initiatives (www.nzfvc.org.nz).

Over the past decade, therefore, responses to domestic violence across sectors have changed dramatically. Multidisciplinary Family Safety Teams have been set up in the main centres around New Zealand to respond to family violence incidents. Family Courts aim to deal with family matters in a manner that is timely and safe (Knaggs, Leahy, Soboleva \& Ong, 2008). There are also Family Violence Victims advisors who provide support to victims of domestic violence.

Notably, one change has been an alteration in the language used to define violence that occurs in the family sphere - the term family violence is more commonly used and encapsulates a number of forms of violence including sibling abuse, elder abuse, child abuse and domestic violence. It has been argued that the use of the term 'family violence' detracts from domestic violence and obscures the gender argument that the majority of violence in the home is perpetuated by men (Merry 2009; Okun, 1986).

Returning to the theory-to-practice framework (Walsh, 2006) we now consider practice models in the context of our changing New Zealand landscape.

\section{Practice models}

The International Federation of Social Work states that:

The social work profession promotes social change, problem solving in human relationships and the empowerment and liberation of people to enhance well-being. Utilising theories of human behavior and social systems, social work intervenes at the points where people interact with their environments. Principles of human rights and social justice are fundamental to social work (IFSW, 2001).

When applying the theory-practice framework (Walsh, 2006) it is clear that social workers who subscribe to micro-oriented explanations of domestic violence may employ practice models that advocate individual counselling, or therapeutic work for the victim and perpetrator. Social workers who subscribe to macro-oriented theories of domestic violence employ practice models that advocate legislative and policy change and focus on empowering 
women to keep safe from domestic violence. Social workers who understand that multiple explanations contribute to our understanding of domestic violence, and that we must understanding the cultural context within which practice occurs, are likely to utilise a range of practice models that are culturally responsive to the client's particular needs. One model that can be useful for social workers as they navigate social work practice in the domestic violence arena is anti-discriminatory practice (ADP).

\section{Anti-discriminatory practice (ADP)}

Anti-discriminatory (also known as anti-oppressive) views have had a significant impact on social work around the world. ADP challenges social workers to examine new ways of working with marginalised populations. ADP began in response to social work practices that maintained prejudice and discrimination. The focus of ADP is self determination through the removal of social, cultural, religious, gender, age, sexuality, economic and political oppression (Okitikpi \& Aymer, 2010). ADP means working to eliminate institutional discrimination that can maintain inappropriate professional social work services to people because of their colour, culture or ethnic origin. Institutional discrimination:

... can be seen or detected in processes, attitudes and behaviour which amount to discrimination through unwitting prejudice, ignorance, thoughtlessness and racist stereotyping which disadvantage minority ethnic people (Macpherson, 1999, p. 28).

Employing ADP as a practice model for working with women who have experienced domestic violence requires social workers to take account of women's social realities. It also necessitates taking account of the socio-structural environment in which women live (Okitikpi \& Aymer, 2010). This means working to ensure that social work services do not further marginalise women. Furthermore, social workers who utilise ADP recognise that cultures are contradictory (Samovar, Porter \& McDaniel, 2010; Sewell, 2005). That is, within a culture there may be common acceptance of domestic violence at the same time as there exists opposition to it. Furthermore, solutions to domestic violence require collaboration across communities and professions (Bent-Goodley, 2007). When collaborating with communities social workers must seek diverse views about the phenomenon - cultures are not homogenous and one voice cannot represent the views of a community. Further, social workers in the domestic violence field should collaborate with other professions and across a range of statutory and non government organisations. Additionally, women who experience domestic violence are part of particular communities, but they are also unique individuals so their response to domestic violence is shaped by a multitude of factors; for example, there is not one way of working with Maori women who experience domestic violence. This is expressed by BentGoodley (2007) who states that 'when we design programs and interventions to meet the needs of everyone, we do little for anyone' (p.98).

Finally, when we work in the domestic violence field, ADP necessitates that we ask the following questions of New Zealand society, the organisations within which social workers carry out their domestic violence work, and of ourselves as practitioners:

- Do we (New Zealand/the organisation) have culturally competent media campaigns - are the campaigns culturally targeted to optimise their impact?

- Are our prevention messages culturally relevant and conveyed in a culturally authentic way? Are we doing more than just translating the same message into different languages? Have we made sure that our prevention messages have meaning within the context of 
the community being targeted? (Bent-Goodley, 2007).

- Does my organisation (and do I) collaborate with other professions and with communities in the struggle against domestic violence?

- In collaboration with communities does the organisation (and do I) seek diverse opinions about how to tackle domestic violence?

- What impact does my social work practice have on marginalised populations?

- How have I developed my ability to be responsive to different cultural expectations?

- How do I challenge organisations and policies that further marginalise women?

- How does the organisation (and how do I) respond to women who say 'Separation from my husband is against my faith'; or, 'I will not leave my community but I still want to be safe'?

\section{Conclusion}

Social work practice in the domestic violence field is complex. The work itself requires that practitioners be both cautious and creative in their micro work with clients. However, this work must be informed by research and theory. In considering New Zealand's response to domestic violence it is clear that a number of theories have influenced the direction of social work practice in the area. It is now apparent that multi-faceted explanations are better able to enhance our understanding of the causes of domestic violence. If we are to be successful in our work with women we must recognise the uniqueness of each woman that enters our organisation while being cognisant of the social and political forces that have contributed to her situation. A way of doing this is to employ an anti-discriminatory model of practice. Lymbery \& Postle (2007) suggest:

Social work ... is a profession that can and should be driven by ideals of equality and social justice. Strength and tenacity to keep those ideals in mind and to work at macro, meso and micro levels are defining features of social work. They make it a profession to be proud of (p. 264).

\section{References}

Balzer, R., Haimona, D., Henare, M., \& Matchitt, V. (1997). Maori family violence in Aotearoa. Wellington: Te Puni Kokiri.

Bandura, A. (1973). Aggression: A social learning analysis. Englewood Cliffs, NJ: Prentice-Hall.

Bandura, A. (1977). Social learning theory. Englewood Cliffs, NJ: Prentice-Hall.

Bandura, A. (1979). The social learning perspective: Mechanisms of aggression. In H. Toch (Ed.), Psychology of crime and criminal justice. New York: Hold, Rinehart \& Winston.

Bent-Goodley, T. B. (2007). Health disparities and violence against women: Why and how cultural and societal influences matter. Trauma, Violence, $\mathcal{E}$ Abuse, 8, 90-104.

Blakely, T., Ajwani, S., Robson, B., Tobias, M., \& Bonne, M. (2004). Decades of disparity: Widening ethnic mortality gaps from 1980 to 1999. 117 (1199). Retrieved from https://www.nzma.org.nz/journal/117-1199/995/.

Bograd, M. L. (1988). Feminist perspectives on wife abuse. In K. Yllo \& M. L. Bograd (Eds.), Feminist perspectives on wife abuse (pp. 11-26). Newbury Park. California: Sage Publications.

Buckingham, J. (2006). Patterns of violence in intimate relationships: A critical examination of legal responses. Doctoral thesis, School of Law, University of Canterbury, Christchurch, New Zealand.

Coady, N., \& Lehmann, P. (2008). Theoretical perspectives for direct social work practice: A generalist-eclectic approach (2nd ed.). New York: Springer.

Cribb, J., \& Barnett, R. (1999). Being bashed: Western Samoan women's responses to domestic violence in Western Samoa and New Zealand. Gender, Place and Culture, March, 49-65.

Crichton-Hill, Y. (2001). Challenging ethnocentric explanations of domestic violence: Let us decide, then value our decisions - a Samoan response. Trauma \& Abuse: A Review Journal, 3(July), 203-214.

Cross, J., \& Newbold, G. (2010). Presumptive arrest in partner assault: Use of discretion and problems of compliance in the New Zealand Police. Australian \& New Zealand Journal of Criminology, 43(1), 51-75.

Dann, C. (1985). The Women's Liberation Movement in New Zealand. A very brief summary of trends. Social Alternatives, 5(1), 24-25. 
Durie, M. (2005). Te Tai Tini Transformations 2025 (CIGAD Working Paper Series 5/2005). Palmerston North: Centre for Indigenous Governance and Development.

Fisher, B. S., \& Lab, S. P. (2010). Encyclopedia of victimology and crime prevention. Thousand Oaks, California: Sage Publications.

Ford, G. (1993). A review of the 1987 police policy on domestic violence. Wellington: Policing Development Group.

Hearn, J. (1998). The violences of men. How men talk about and how agencies respond to men's violence to women. London. Thousand Oaks: Sage Publications.

International Federation of Social Workers (2001). Definition of social work. From http://www.ifsw.org/p38000279. html.

Knaggs, T., Leahy, F., Soboleva, N., \& Ong, S. (2008). The Waitakere and Manukau Family Violence Courts: An evaluation summary. Wellington: Ministry of Justice.

Lymbery, M., \& Postle, K. (2007). Social work: a companion to learning. London: Sage Publications.

Macpherson, S. W. (1999). The Stephen Lawrence Inquiry. London: The Stationery Office.

McPhail, B. A., Busch, N. B., Kulkarni, S., \& Rice, G. (2007). An integrative feminist mode. The evolving feminist perspective on intimate partner violence. Violence Against Women, 13(8), 817-841.

Merry, S. E. (2009). Gender violence: A cultural perspective. Chicester: Blackwell Publishing.

New Zealand. Committee of Inquiry into Violence (1987). Report of Ministerial Committee of Inquiry into Violence. Wellington: Department of Justice.

New Zealand. Ministerial Advisory Committee on a Maori Perspective for the Department of Social Welfare., \& Rangihau, J. T. R.-A. (1986). Puao-te-ata-tu=day break: The report of the Ministerial Advisory Committee on a Maori Perspective for the Department of Social Welfare. Wellington, N.Z.: The Committee.

Okitikpi, T., \& Aymer, C. (2010). Key concepts in anti-discriminatory social work. Los Angeles, California; London: Sage.

Okun, L. (1986). Women abuse: Facts replacing myths. New York: State University of New York Press.

Renfrew, J. W. (1997). Aggression and its causes: A biopsychosocial approach. New York: Oxford University Press.

Ricketts, D., \& Childs, T. (1991). I've got to go now (recorded by Toni Childs). On House of Hope. A \& M Records.

Samovar, L. A., Porter, R. E., \& McDaniel, E. R. (2010). Communication between cultures. Boston: Wadsworth Cengage Learning.

Schechter, S. (1982). Women and male violence: The visions and struggles of the battered women's movement. Boston: South End Press.

Sewell, W. H. (2005). A theory of structure: duality, agency and transformation. In G. M. Spiegel (Ed.), Practicing history. New directions in historical writing after the linguistic turn. New York: Routledge.

Sheldon, B., \& Macdonald, G. (2009). A textbook of social work. New York: Routledge.

Shardlow, S. M. (2007). The social policy context of practice learning. In J. Lishman (Ed.), Handbook for practice learning in social work and social care knowledge and theory. (pp. 13-26). London; Philadelphia: Jessica Kingsley Publishers.

Stith, S. M., Rosen, K. H., Middleton, K. A., Busch, A. L., Lundeberg, K., \& Carlton, R. P. (2000). The intergenerational transmission of spouse abuse. A meta-analysis. Journal of Marriage and Family, 62(3), 640-654.

The Ministry of Social Development (2002). Te Rito: New Zealand Family Violence Prevention Strategy. Wellington: The Ministry of Social Development.

Verrill, S. W. (2008). Social structure-social learning and delinquency: Mediation or moderation? New York: LFB Scholarly Publishing.

Walsh, J. (2006). Theories for direct social work practice. Belmont, CA: Thomson Brookes/Cole. 